\title{
Reinigung der ätherischen Oele der Drupaceen.
}

Prof. Göpp ert hat wiederholt darauf angetragen, dass durch polizelliche Verordnung die Destillation der blausäurehaltigen ätherischen Dele über eine alkalische Salzbasis sanitätspolizeilich vorgeschrieben werde, und durch Versuche nachgewiesen, dass auf diese Weise das Cyan oder die Blansaure grösstentheils daraus entfernt und die Oele in ihrer giftigen Eigenschaft bedeutend geschwächt werden, was von grosser Wichtigkeit ist, weil der Verbrauch der ätherischen Oele der Drupaceen zu Luxusgegenständen enorm ist, und schon öfters tödtliche Vergiftungen, theils zufällig, theils absichtlich dadurch veranlasst worden sind. (Buchn. Repert. Bd. 47. H/t.2)

Overbeck

\section{Ol. Ricini alcoholicum.}

Unter diesem Namen kommt jetzt uber Triest ein Oel in den Handel, welches namentlich in Italien viel Anklang findet, und wovon $\frac{1}{2}-1$ Loth dieselbe Wirkung üben, wie 2-4 Loth von dem gewöhnlichen Ricinusöl. Es ist sehr blass ölgelb und etwas trube, hat einen schwachen alkoholischen Geruch und 'einen nicht unangenehmen öligen zugleich weingeistigen Geschmack, im Schlunde einen kratzenden Reiz hinterlassend. Nach Buch ner enthält es 72 Proc. gewöhnliches Ricinusöl in Verbindung mit den drastischen Bestandiheilen der Samen nebst 28 Proc. Alkohol und Wasser. Buchner stellt die Vermuthung auf, dass das Ol. Ricini alcoholicum nichts anderes. als ein weingeistiger Auszug des Ricinussamens sei, und dass es seine stärkere Purgirkraft dem drastischen, in Weingeist löslichen Stoffe der Samen verdanke, welcher in dem milden, durchs Auskochen mit Wasser gewonnenen Ricinusöle nur in selır geringer Menge enthalten ist. (Buchn. Repert. Bd, 17. Bft. 2.) Overbeck.

\section{Zur pharmakologischen lienntniss des indischen Haufs und des Molnns.}

Prof. Dr. Riegler berichtet aus Constantinopel, dass die den Aethereinathmungen zu Grunde liegende Idee nicht neu sei, indem bei den Indiern schon seit den ältesten Zeiten eine Arznei im Gebrauch gewesen, welche den zu Operirenden der freien Ausübung seiner Sinne beraubt, und auf kurze Zeit unempfindlich mache. Diese 